\title{
The driving processes of concurrent hot and 2 dry extreme events in China
}

\section{Article}

Published Version

Creative Commons: Attribution 4.0 (CC-BY)

Open Access

Tian, F., Klingaman, N. P. ORCID: https://orcid.org/0000-00022927-9303 and Dong, B. ORCID: https://orcid.org/0000-00030809-7911 (2021) The driving processes of concurrent hot and 2 dry extreme events in China. Journal of Climate, 34 (5). pp. 1809-1824. ISSN 1520-0442 doi: https://doi.org/10.1175/JCLID-19-0760.1 Available at https://centaur.reading.ac.uk/93824/

It is advisable to refer to the publisher's version if you intend to cite from the work. See Guidance on citing.

To link to this article DOI: http://dx.doi.org/10.1175/JCLI-D-19-0760.1

Publisher: American Meteorological Society

All outputs in CentAUR are protected by Intellectual Property Rights law, including copyright law. Copyright and IPR is retained by the creators or other copyright holders. Terms and conditions for use of this material are defined in the End User Agreement.

\section{www.reading.ac.uk/centaur}

\section{CentAUR}

Central Archive at the University of Reading 
Reading's research outputs online 


\title{
๖The Driving Processes of Concurrent Hot and Dry Extreme Events in China
}

\author{
FAngXing Tian, ${ }^{\mathrm{a}}$ Nicholas P. Klingaman, ${ }^{\mathrm{a}}$ AND BuWEN DONG ${ }^{\mathrm{a}}$

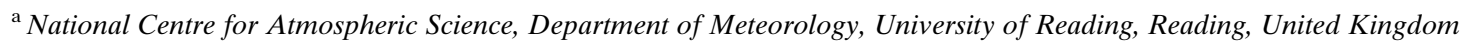

(Manuscript received 11 October 2019, in final form 23 October 2020)

\begin{abstract}
Subseasonal heatwave-driven concurrent hot and dry extreme events (HDEs) can cause substantial damage to crops, and hence to lives and livelihoods. However, the physical processes that lead to these devastating events are not well understood. Based on observations and reanalysis data for 1979-2016 over China, we show that HDEs occur preferentially over central and eastern China (CEC) and southern China (SC), with a maximum of three events per year along the Yangtze Valley. The probability of longer-lived and potentially more damaging HDEs is larger in SC than in CEC. Over SC the key factors of HDEs - positive anomalies of surface air temperature and evapotranspiration, and negative anomalies of soil moisture-begin two pentads before maximizing at the peak of the HDEs. These anomalies occur south of a positive height anomaly at $200 \mathrm{hPa}$, associated with a large-scale subsidence anomaly. The processes over CEC are similar to those for SC, but the anomalies begin one pentad before the peak. HDE frequency is strongly related to the Silk Road pattern and the boreal summer intraseasonal oscillation. Positive phases of the Silk Road pattern and suppressed phases of the boreal summer intraseasonal oscillation are associated with positive height anomalies over CEC and SC, increasing HDE frequency by about $35 \%-54 \%$ relative to the climatological mean. Understanding the effects of subseasonal and seasonal atmospheric circulation variability, such as the Silk Road pattern and boreal summer intraseasonal oscillation, on HDEs is important to improve HDE predictions over China.
\end{abstract}

KEYWORDS: Atmosphere-land interaction; Rossby waves; Drought; Madden-Julian oscillation; Monsoons; Surface temperature

\section{Introduction}

Drought has destructive impacts on agriculture (Zhang et al. 2015), water resources (Shukla et al. 2015), human health (Stanke et al. 2013), and natural ecosystems (van Dijk et al. 2013). Previous studies have mainly focused on three characteristics of drought: intensity, duration, and spatial coverage (Dai 2011). Conventional drought is usually considered to develop slowly, over one or several seasons. However, recent studies have shown that the impacts of concurrent droughts and heatwaves could be more serious compared to their individual occurrences (Sharma and Mujumdar 2017). If extreme weather conditions, such as heatwaves, persist over a region for several weeks, drought can develop very rapidly (Otkin et al. 2015; Mo and Lettenmaier 2015). These rapidly developing droughts concurrent with heatwaves are termed "heatwave flash droughts" (heatwave FDs; Ford and Labosier 2017).

China has experienced severe FDs during the last few decades. For example, FDs in July 2013 affected agriculture in South China (Yuan et al. 2015). Heatwave FDs are likely in regions with sufficient soil moisture supply (Wang and Yuan 2018). As shown by Piao et al. (2010), the agricultural regions of China are found mainly in East and South China, where soil moisture is plentiful, which makes crop production in China more sensitive to heatwave FDs. FDs over the Gan River Basin in China were studied in Zhang et al. (2017), which shows that

\footnotetext{
¿ Denotes content that is immediately available upon publication as open access.

Corresponding author: Fangxing Tian, fangxing.tian@reading. ac.uk
}

heatwave FDs are more common in northern part of the basin and that their frequency has increased significantly since 1997. In contrast to conventional droughts, there is no universally accepted definition of FDs (Yuan et al. 2019). Individual studies identify FDs in different ways, depending on their main purpose, such as to understand FD mechanisms in the presentday climate or project future changes in FD occurrence. However, poor understanding of the large-scale circulation processes related to FDs makes FD predictions challenging (Otkin et al. 2013, 2014, 2015, 2018a,b). Since heatwave FDs are rapidly developing concurrent hot and dry events (Yuan et al. 2019), this work aims to understand the driving processes of heatwave-driven concurrent hot and dry extreme events (HDEs) over China. Understanding the mechanisms related to all HDEs will contribute to understanding rapidly developing HDEs, such as heatwave FDs.

The development of HDEs is related to the persistence of high surface air temperatures, low relative humidity, strong surface winds, and reduced cloud cover for days or weeks. These conditions can force a transition from energy-limited evapotranspiration (ET) to water-limited ET, and lead to rapid increases in vegetation stress (Ford and Labosier 2017). In this work we consider HDEs with concurrent decreased soil moisture, anomalously high temperatures, and increased ET (Hunt et al. 2009). Over China, the coincidence of these conditions is normally related to large-scale subsidence, which can be controlled by the well-known Silk Road atmospheric wave pattern (SRP; He et al. 2018). Since HDEs normally have a

This article is licensed under a Creative Commons Attribution 4.0 license (http://creativecommons.org/ licenses/by/4.0/). 

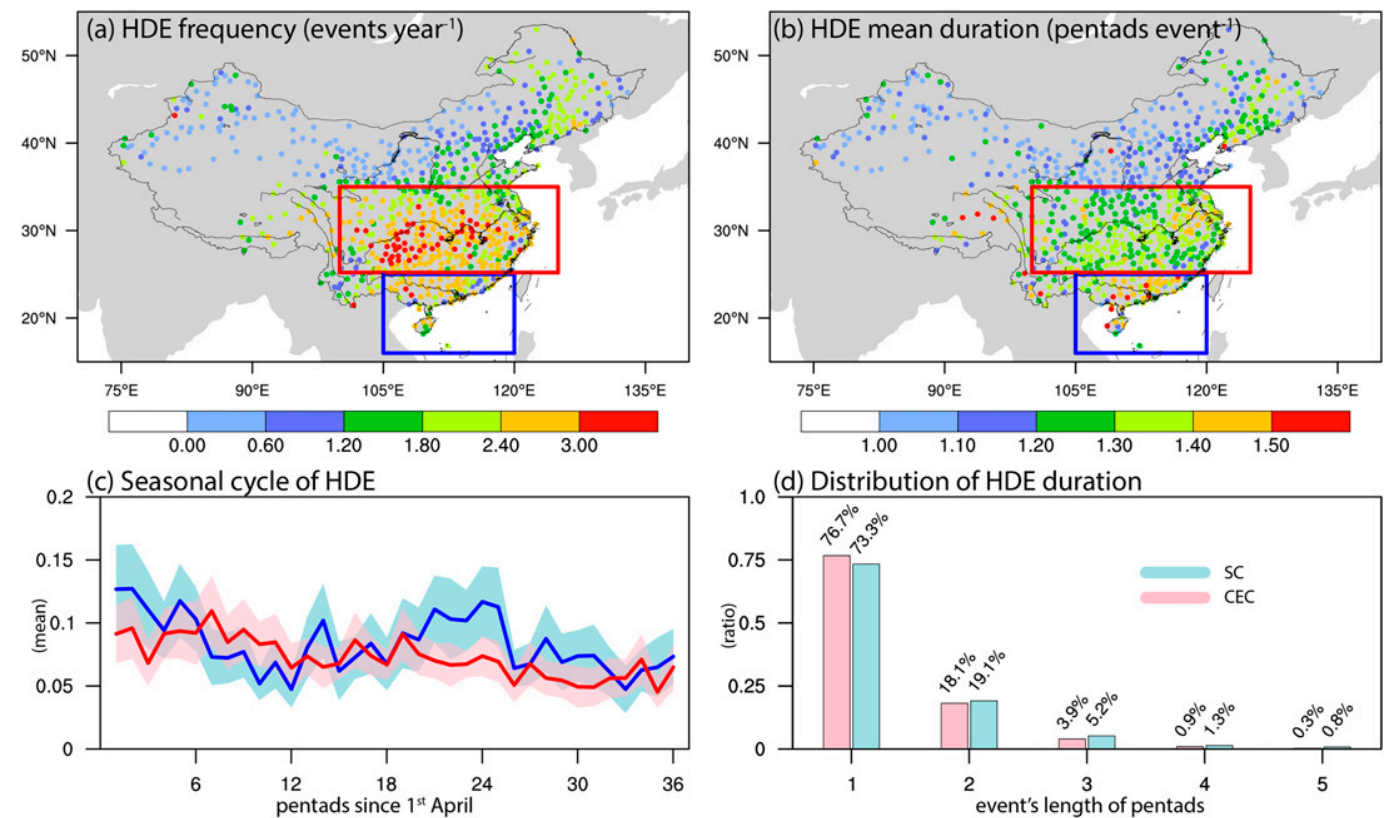

(e) Seasonal cycle of in SC
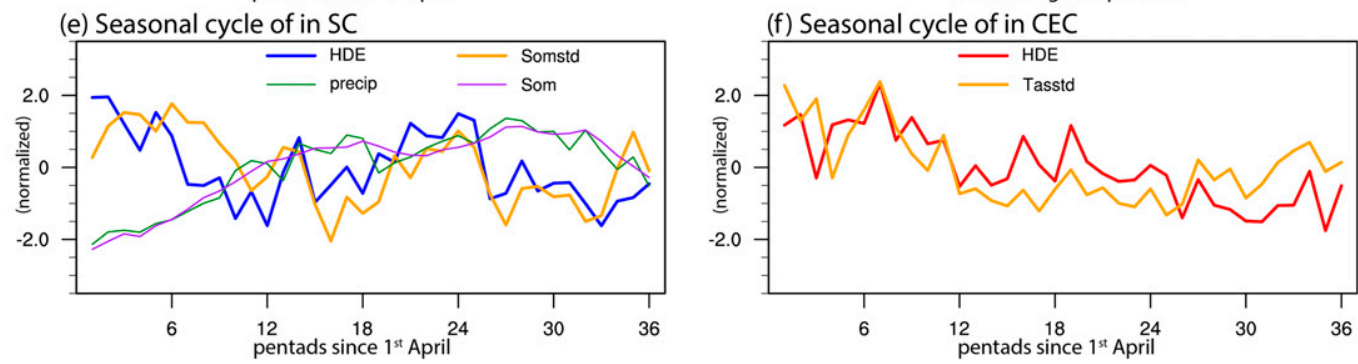

FIG. 1. (a) HDE frequency over China in the growing season (April-September) averaged during 1979-2016 (events per year). Red and blue boxes outline central and eastern China and southern China. (b) As in (a), but for mean duration of HDE (pentads per event). (c) Mean seasonal cycle of HDE frequency over southern China (blue) and central and eastern China (red). The shading highlights the range between the mean plus or minus one standard deviation of the interannual variability. (d) Distribution of HDE duration over central and eastern China (pink) and southern China (light blue). (e) Normalized seasonal variability of HDE frequency (blue) and standard deviation of soil moisture (orange). Mean precipitation (green) and mean soil moisture (purple) in southern China. (f) Normalized seasonal cycle of HDE frequency (red) and standard deviation of near-surface air temperature (orange) in central and eastern China.

duration of 5-10 days (Wang et al. 2016), subseasonal-scale circulation variations, such as the boreal summer intraseasonal oscillation (BSISO), may modulate HDE frequency. Therefore, by understanding local physical processes leading to the HDEs and their relationships with large-scale circulation variability, this work bridges the gap between the detailed process-level HDE studies and the well-studied SRP and BSISO.

In the midlatitudes, synoptic to subseasonal circulation variability is related to wave trains, such as the SRP. For example, 7-20-day convective variability around and over the Tibetan Plateau is associated with a wave train propagating from North Africa to Japan (Fujinami and Yasunari 2004). To study the effect of midlatitude waves on HDEs in China, the SRP index (SRPI) defined in Yasui and Watanabe (2010) is used in this work.

The BSISO has a 30-60-day component (BSISO1; Lee et al. 2013), with northward off-equatorial propagation coupled to equatorial eastward propagation, and a 10-30-day component (BSISO2) with northwestward propagation from the west
Pacific (Mao and Chan 2005). Chen and Zhai (2017) noticed that BSISO1 phases 2-4 were associated with a fourfold to fivefold increase in the frequency of extreme high temperatures in South China and southeastern China, along with subsidence anomalies. These conditions might trigger HDEs. To study the relationship between HDEs and the BSISO, the BSISO indices developed by Lee et al. (2013) are adopted.

The structure of this paper is as follows. Section 2 describes the data and methods. The results are shown in section 3 and discussed further in section 4 . The conclusions are summarized in section 5 .

\section{Data and methods}

\section{a. Observational and reanalysis datasets}

To identify HDEs, daily near-surface air temperature (Tas), evapotranspiration (ET), and soil moisture (SM; to 1-m depth) are required. Daily Tas data are taken from a homogenized 

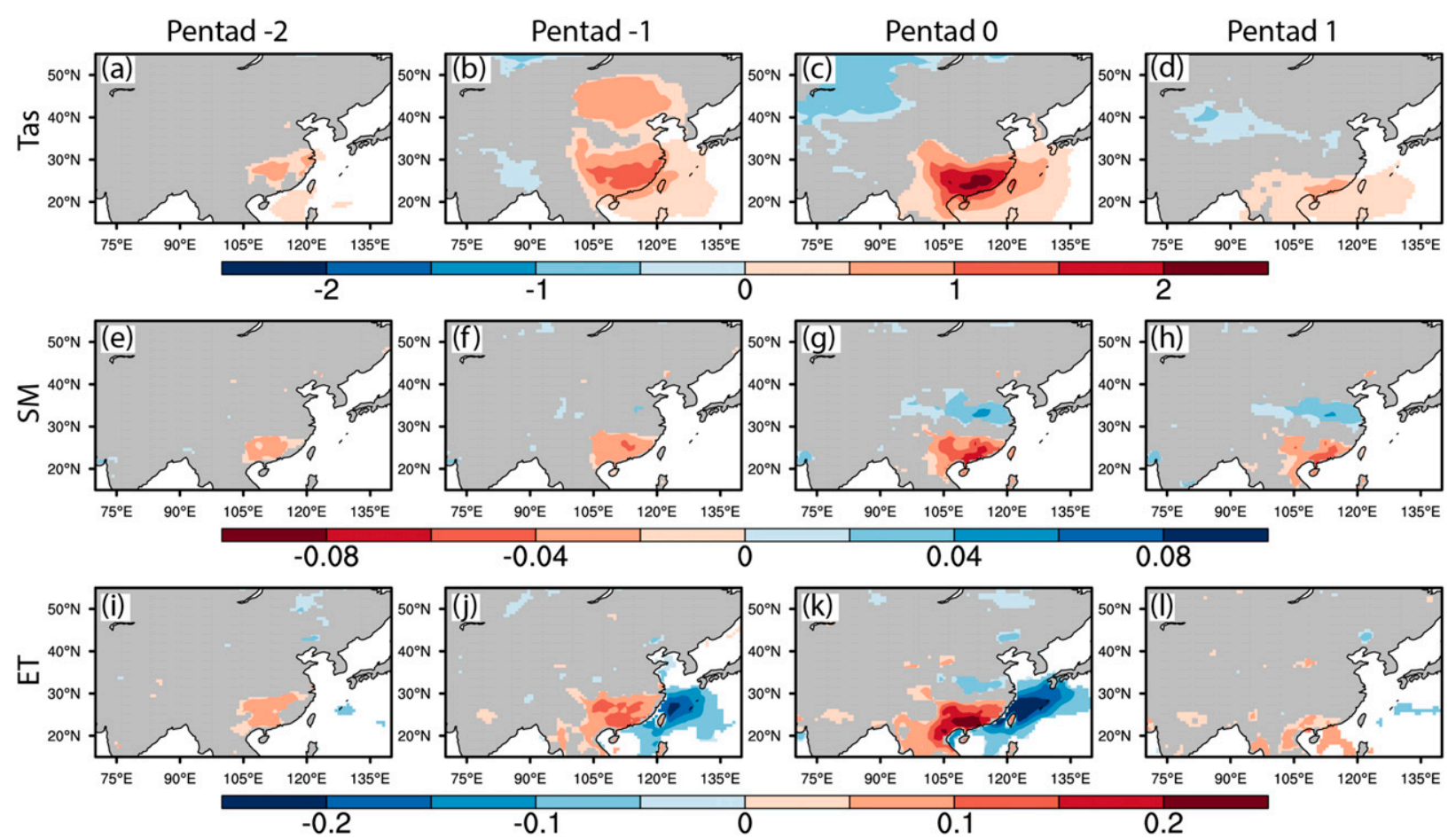

FIG. 2. Composited Tas $\left({ }^{\circ} \mathrm{C}\right), \mathrm{SM}\left(\mathrm{m}^{3} \mathrm{~m}^{-3}\right)$, and $\mathrm{ET}\left(\mathrm{mm} \mathrm{day}^{-1}\right)$ in the peak pentad (pentad 0$)$, one and two pentads before the peak pentad (pentad -1 and -2 ), and one pentad after the peak pentad (pentad 1). Color indicates where the anomalies are statistically significant at the 5\% level using a two-tailed Student's $t$ test. Peak pentads are defined when the area-averaged HDE frequency over southern China is larger than its 90th percentile. The area average is computed within the blue box shown in Fig. 1a.

dataset of 753 stations over China during 1979-2016 (Li et al. 2016). This dataset is quality controlled by the Climate Data Centre (CDC) of the National Meteorological Information Centre, China Meteorological Administration (CMA). Station density is highest in central and eastern China and southern China, the domain used in this study. The HDEs from station near-surface temperature data are compared with those from the European Centre for Medium-Range Weather Forecasts interim global reanalysis at $0.7^{\circ}$ resolution (ERA-Interim; Dee et al. 2011). The analysis demonstrates that the spatial distribution and temporal variability of HDEs from ERA-Interim resemble those of HDEs from station data (not shown). This implies that HDE statistics and HDE-associated circulation anomalies are not sensitive to whether surface air temperatures from ERA-Interim or station observations are used. However, considering the higher accuracy of station observations than reanalysis data, as well as the reasonable record length and spatial distribution of station observations, we choose to employ station temperatures in this study. ET is calculated from daily latent heat flux from ERA-Interim (Dee et al. 2011). SM data are also taken from ERA-Interim. The sum of the top three layers of soil moisture in ERA-Interim is taken as the 1-m integrated soil moisture. To examine the sensitivity to uncertainty in reanalysis soil moisture, we compared our maps of mean HDE frequency with those from previous work based on the Global Land Data Assimilation System version 2 (GLDAS-2) data (Wang et al. 2016, 2018).
The distribution, duration, and decadal change of HDEs generated with these different datasets are similar, although the dates of individual events will not be consistent with previous studies due to the change in reanalysis dataset. Our event set is physically consistent with the HDE criteria applied and with the ERA-Interim circulation, which we use to examine HDE teleconnections to large-scale phenomena. We use ERA-Interim data for the remainder of the study.

Beyond identifying HDEs, we investigate the physical processes associated with HDEs. For the physical processes, we analyze the following daily fields from ERA-Interim: Tas, horizontal wind at $10 \mathrm{~m}, 850 \mathrm{hPa}$, and $200 \mathrm{hPa}$, vertical velocity at $500 \mathrm{hPa}$, geopotential height at $200 \mathrm{hPa}$, surface solar radiation, precipitation, cloud cover, and outgoing longwave radiation (OLR).

\section{b. Methods}

\section{1) CONCURRENT HOT AND DRY EXTREME EVENTS}

Based on Mo and Lettenmaier (2015), hot and dry extreme events (HDEs) are defined based on pentad means, using three criteria: 1) Tas anomaly $>$ one standard deviation (STD) computed from the base period of that pentad, 2) ET anomaly $>0$, and 3) SM less than its 40th percentile. For each pentad and each grid point, an HDE is identified when all above requirements are satisfied. As HDEs are most important for their effects on the agriculture, we consider only the growing season, defined as 1 April to 30 September following 

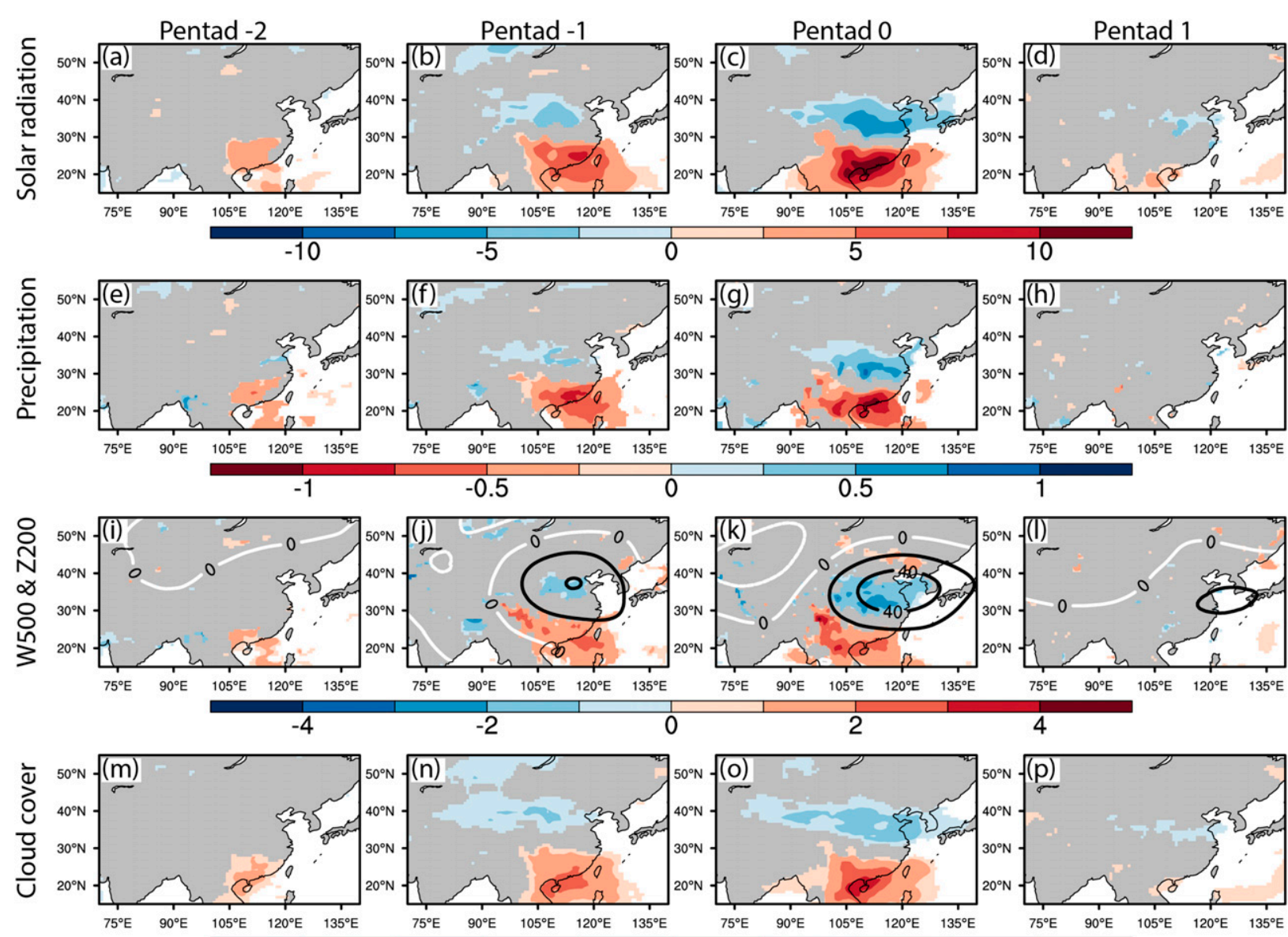

$-0.2$

$-0.1$

0.1

0.2

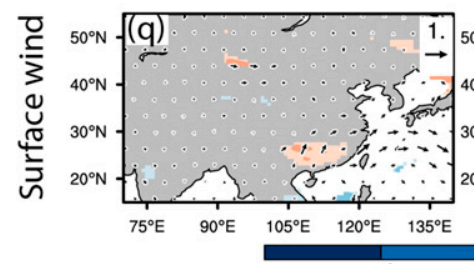

$-1$
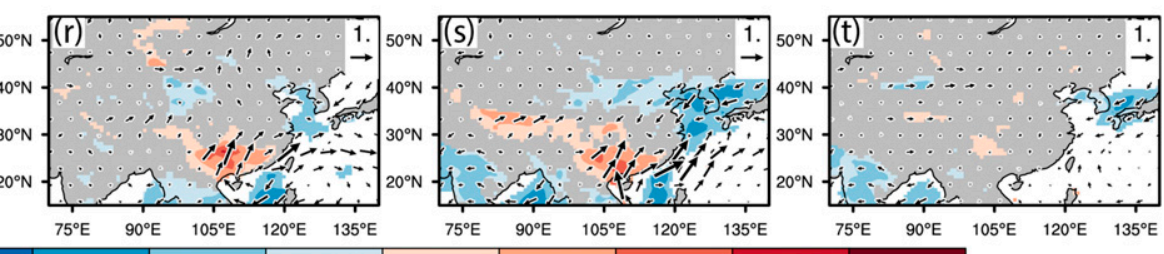

$-0.5$

0.5

1

FIG. 3. (a)-(d) Composited surface net solar radiation $\left(\mathrm{W} \mathrm{m}^{-2}\right)$, (e)-(h) precipitation $\left(\mathrm{mm} \mathrm{day}^{-1}\right)$, (i)-(l) 500 -hPa vertical velocity (colors; $10^{-2} \mathrm{~Pa} \mathrm{~s}^{-1}$ ) and 200-hPa geopotential height (contour; $\left.\mathrm{m}\right),(\mathrm{m})-(\mathrm{p})$ cloud cover, and $(\mathrm{q})-(\mathrm{t})$ surface wind (arrows) and wind speed (colors; $\mathrm{m} \mathrm{s}^{-1}$ ) in the peak pentad (pentad 0), one and two pentads before the peak pentad (pentads -1 and -2 ), and one pentad after the peak pentad (pentad 1). Color indicates where the anomalies are statistically significant at the $5 \%$ level using a two-tailed Student's $t$ test. Peak pentads are defined when the area-averaged HDE frequency over southern China is larger than its 90 th percentile. The area average is computed within the blue box shown in Fig. 1a.

Hunt et al. (2009). To ensure the dominant role of heatwaves in triggering and enhancing HDEs (i.e., high temperature increases the total ET), we require positive ET anomalies. This shortens the duration of HDEs, compared to using negative ET anomalies, because events of simultaneous, anomalously positive Tas and ET are short-lived (Mo and Lettenmaier 2015).

\section{2) HDE PENTADS AND FREQUENCY}

HDEs are identified based on Tas from station observations, and SM and ET from ERA-Interim. We first select the SM and ET from the ERA-Interim grid points nearest to each observation station. Second, at each grid point, we compute the total number of events and pentads of HDEs in each year over the entire record. The HDE pentads are defined as the annualmean number of pentads per year under HDEs. The HDE frequency is the annual-mean number of HDEs per year. The duration is calculated by averaging the duration of all HDE events (pentads per event).

\section{3) COMPosite HDEs}

In China, HDEs are mainly found in central and eastern China (CEC) and southern China (SC) (see section 3a). To 

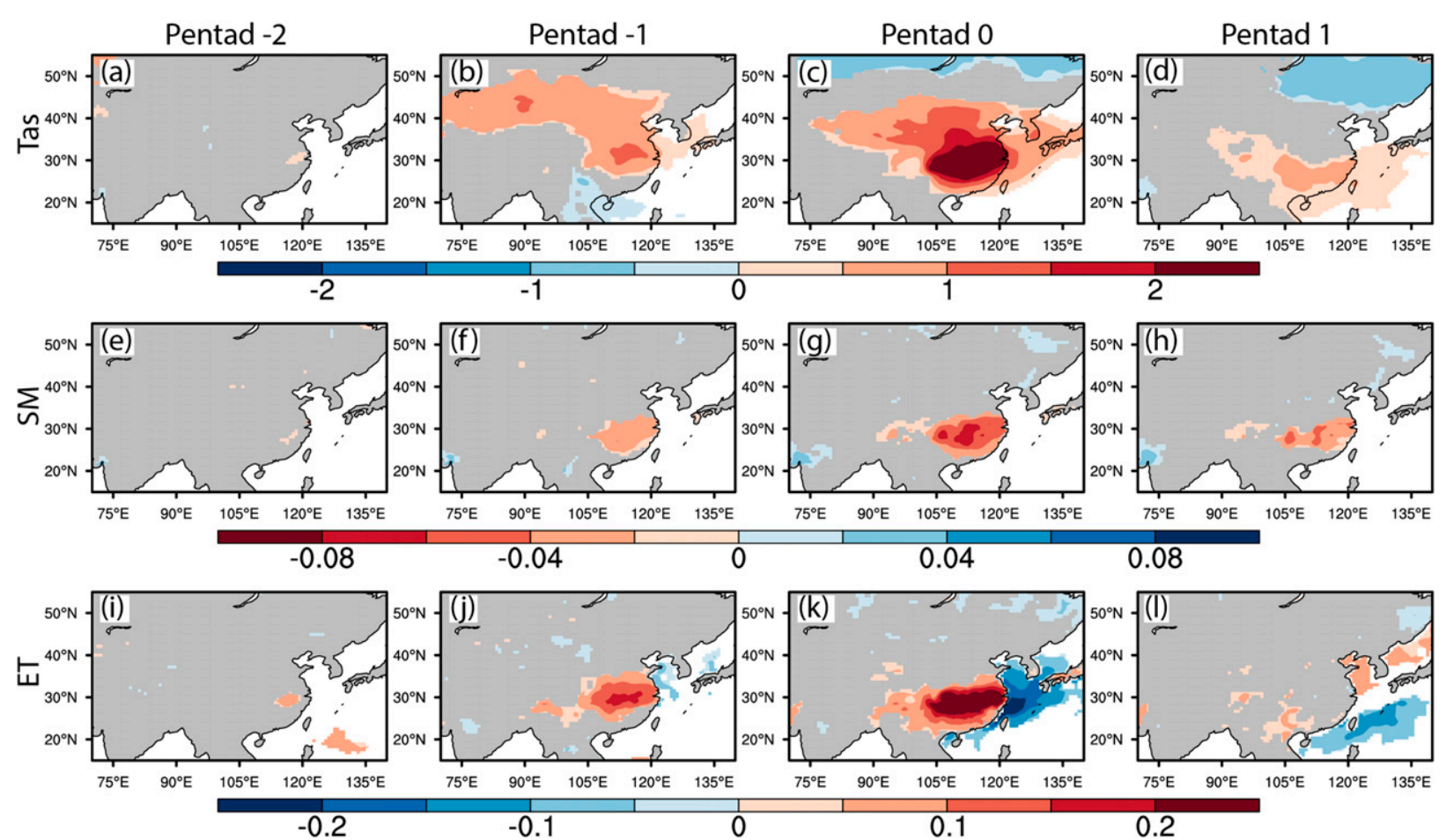

FIG. 4. As in Fig. 2, but based on peak pentads over central and eastern China, within the red box shown in Fig. 1a.

compare the physical processes in the two regions, we composite HDEs in $\mathrm{CEC}\left(25^{\circ}-35^{\circ} \mathrm{N}, 100^{\circ}-125^{\circ} \mathrm{E}\right)$ and $\mathrm{SC}\left(16^{\circ}-25^{\circ} \mathrm{N}\right.$, $\left.105^{\circ}-120^{\circ} \mathrm{E}\right)$ separately. We first generate two time series with the regionally averaged $\mathrm{HDE}$ frequencies over $\mathrm{CEC}$ and SC. Second, we isolate pentads with HDE frequencies larger than the 90th percentile of the time series, which indicate widespread HDEs (not necessarily intense HDEs) that we hypothesize are more likely to be linked to large-scale circulation variability. These pentads are termed "peak events" (hereafter pentad 0 ). Next, we composite circulation fields on the peak events (pentad 0 ), one and two pentads before the peak events (hereafter pentad -1 and pentad -2 ) and one pentad after the peak events (hereafter pentad +1 ).

\section{4) SILK ROAD PATTERN}

To investigate the relationship between HDEs and midlatitude subseasonal atmospheric circulation variability, we compute the Silk Road pattern (SRP) index defined by Yasui and Watanabe (2010). The SRP is obtained through empirical orthogonal function (EOF) analysis on the 200-hPa meridional wind anomaly in the region $20^{\circ}-60^{\circ} \mathrm{N}, 0^{\circ}-150^{\circ} \mathrm{E}$. The first two leading modes are defined as the SRP1 and SRP2. The SRP indices (SRP1I and SRP2I) are the time series of the first two principal components (PC1 and PC2). The pentads when the SRP1I or SPR2I are more than one standard deviation above their respective means are selected as strong SRP pentads. To quantitatively estimate the SRP-related anomalies, we selected the strong SRP pentads from the pentads when the HDE frequencies are larger than their respective means plus one standard deviation. In the selected pentads, we have strong
SRP and high HDE frequency events, which are named SRP1HDEs or SRP2-HDEs.

\section{5) BOREAL SUMMER INTRASEASONAL OSCILLATION}

To connect HDEs over China to tropical subseasonal atmospheric circulation variability, we compute the pentad-mean boreal summer intraseasonal oscillation (pentad-BSISO) index from the daily BSISO indices of Lee et al. (2013). The BSISO indices are computed using multivariate EOF analysis of normalized daily mean OLR and 850 -hPa zonal wind anomalies over the Asian summer monsoon region $\left(10^{\circ} \mathrm{S}-40^{\circ} \mathrm{N}, 40^{\circ}-\right.$ $\left.160^{\circ} \mathrm{E}\right)$. The anomalies are computed by removing the mean and first three harmonics of the annual cycle, then removing the mean of the previous 120 days. The PC time series of the leading two modes (PC1 and PC2) define BSISO1; the PC time series of the third and fourth modes (PC3 and PC4) define BSISO2. We compute pentad-mean BSISO1 and BSISO2 by first forming pentad means of the four normalized PC time series, and then computing amplitude and phase based on the pentad means.

\section{Results}

\section{a. Climate state}

The long-term mean of HDE frequency (Fig. 1a) shows that HDEs are broadly distributed across China with the highest HDE frequency over CEC. The maximum is above three events per year along the Yangtze River. The average duration of HDEs (Fig. 1b) indicates that HDEs over SC typically last 

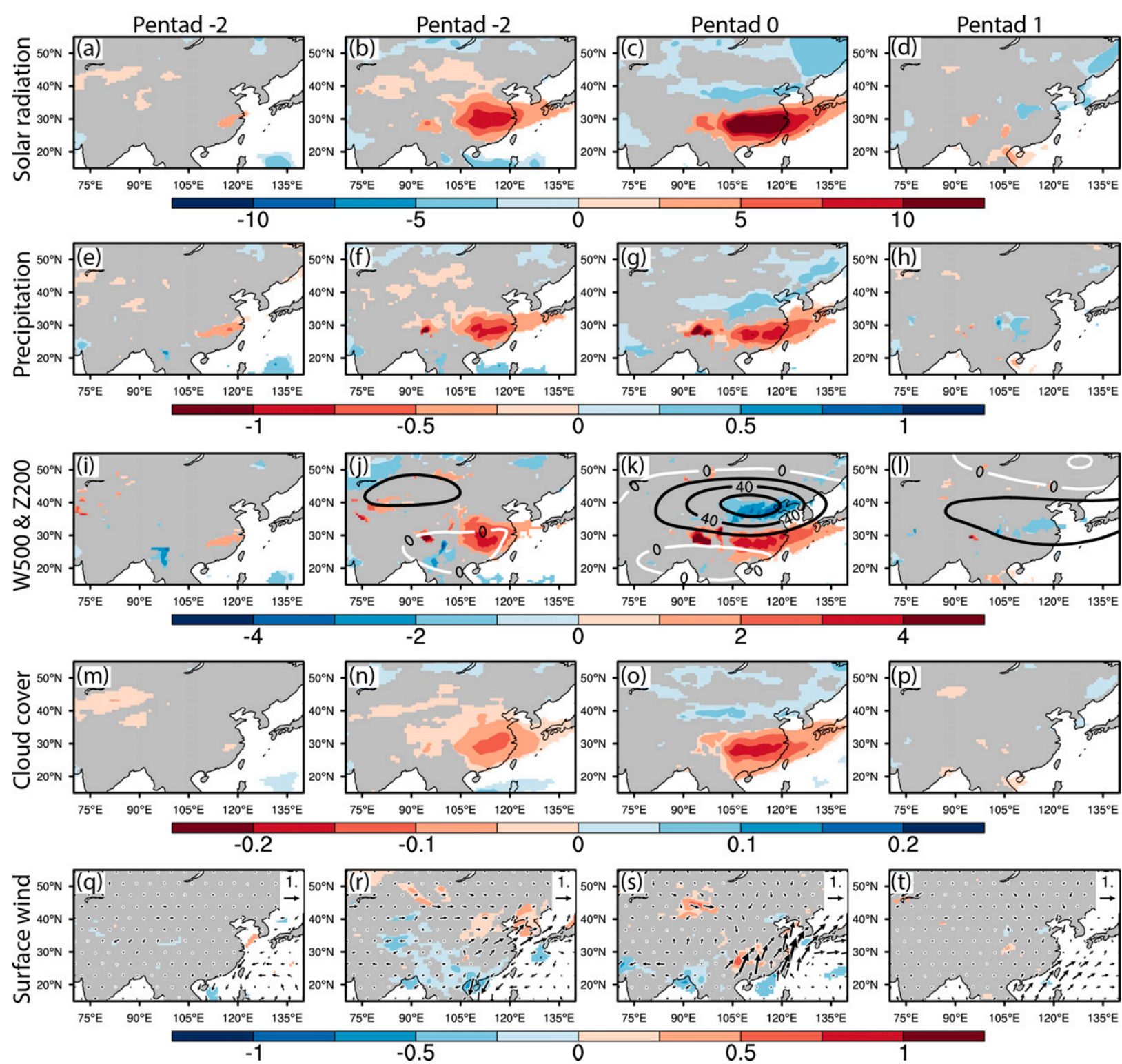

0.2

FIG. 5. As Fig. 3, but based on peak pentads over central and eastern China, within the red box shown in Fig. 1a.

longer than those over CEC. Over SC, the average duration is up to 1.5 pentads; over CEC, the average duration is about 1.3 pentads. The probability of long-lived HDEs (with duration longer than two pentads) is larger in SC (26.7\%) than in CEC (23.3\%) (Fig. 1d). Therefore, we use SC and CEC as key regions for further analysis.

Another important difference between HDEs over the two key regions is the seasonality (Fig. 1c). Over CEC, HDEs have a weak seasonal cycle. The frequency in spring (AprilMay) is only slightly higher than in other months. Over SC, however, HDEs have a more pronounced seasonal cycle, with maxima in April and July-August, and a minimum in May. The stronger seasonality of HDEs over SC is dominated by variations in SM and precipitation (Fig. 1e). In April and May (pentads 1-12), declining HDE frequency is consistent with high SM and more precipitation, because the soil moisture depletion by evapotranspiration will be easily replenished by frequent precipitation, leading to stable and high soil moisture and small possibility of HDEs. After May (pentad 12), HDE frequency in southern China is linked to SM variability, as well as the mean seasonal cycle of precipitation and SM. The connection to SM variability shows that HDEs are more frequent when SM is more variable, and less frequent when SM is high and less variable. SM variability is higher during periods when SM is relatively low, likely because these periods are characterized by less consistent precipitation during "breaks" in the summer monsoon. In central and eastern China, HDE frequency variations are linked to variations in Tas, which has a 

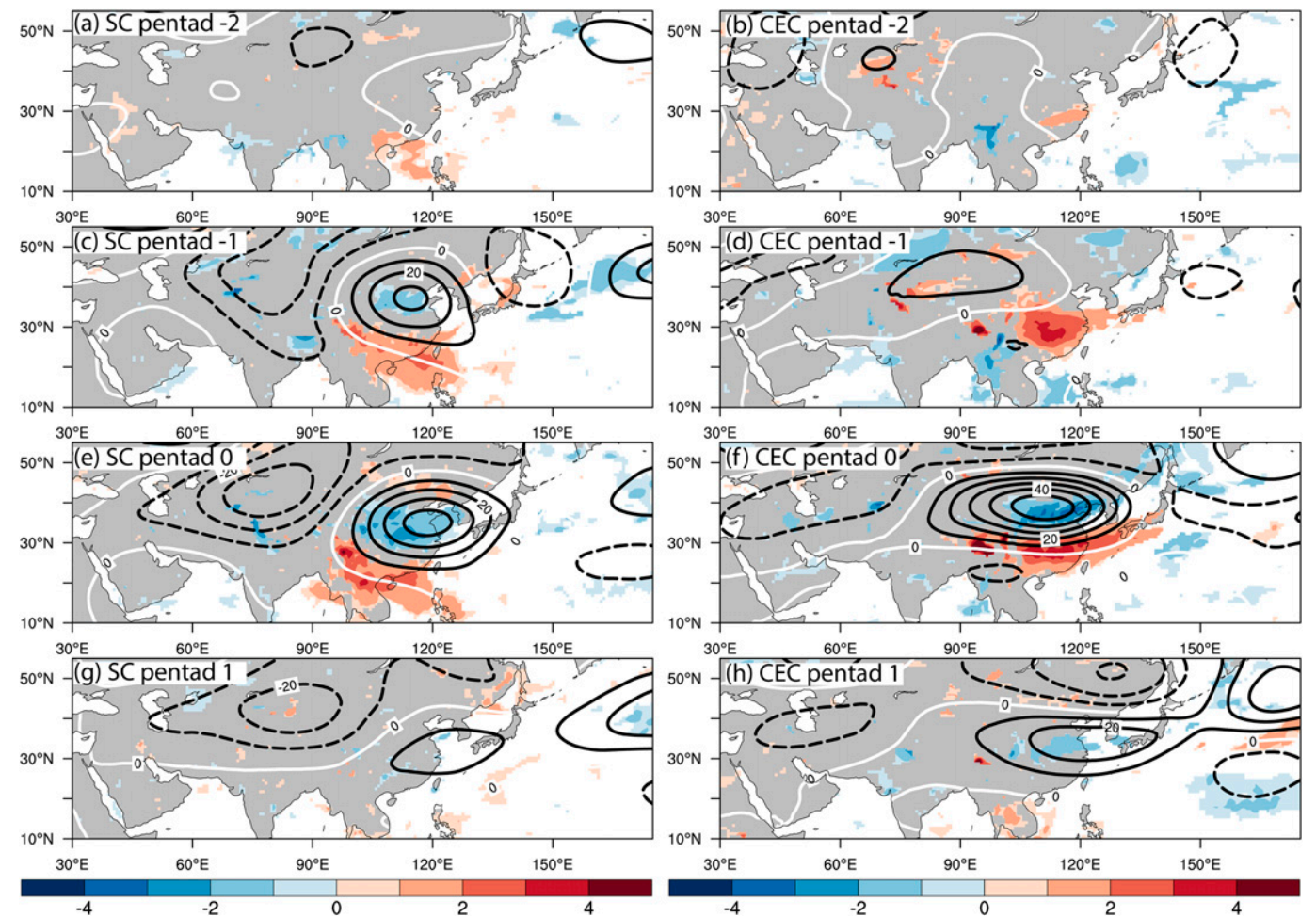

FIG. 6. Composite 500-hPa vertical velocity (colors; $10^{-2} \mathrm{~Pa} \mathrm{~s}^{-1}$ ) and $200-\mathrm{hPa}$ geopotential height (contours; $\mathrm{m}$ ) anomalies based on time series of HDE frequency larger than 90th percentile over (left) southern China and (right) central and eastern China. Colors indicate where the anomalies are statistically significant at the $5 \%$ level using a two-tailed Student's $t$ test.

maximum in early May (pentad 7) and decreases slowly with time (Fig. 1f).

\section{b. Regional processes}

\section{1) SOUTHERN CHINA}

To understand the physical processes related to the evolution of HDEs over SC, we composited surface and atmospheric variables related to HDEs across four pentads: pentad -2 to pentad +1 . The composites are based on pentads when the regional averaged HDE frequency is larger than its 90th percentile [details in section $2 \mathrm{~b}(3)$ ]. The composited variables are Tas (Figs. 2a-d), SM (Figs. 2e-h), and ET (Figs. 2i-1). The composites at pentads -2 and -1 indicate the developing processes of HDEs. The warm anomalies of Tas begin at pentad -2 , reach their maximum at pentad 0 , and diminish rapidly in pentad +1 . The anomalies of SM and ET develop and decay simultaneously with Tas.

The Tas warm anomalies are related to positive anomalies of surface solar radiation (Figs. 3a-d), which can warm the land surface and increase Tas via elevated sensible heat fluxes. Over $\mathrm{SC}$, ET is determined by the amount of energy available to evaporate water. Since solar radiation is the dominant energy source, positive anomalies of solar radiation increase ET. ET is further amplified by warmer Tas (Figs. 2a-d) and higher surface wind speeds (Figs. $3 \mathrm{~m}-\mathrm{p}$ ). The dry SM (Figs. 2e-h) is partly related to reduced precipitation (Figs. $3 \mathrm{e}-\mathrm{h}$ ); $\mathrm{SM}$ is further reduced by positive ET anomalies (Figs. 2i-1).
The analysis of the key factors of HDEs shows that HDEs are related to the simultaneous occurrence of increased solar radiation, reduced precipitation, and higher surface wind speed. Increased solar radiation is associated with reduced cloud cover (Figs. 3m-p). Reduced cloud cover is consistent with anomalous subsidence at $500 \mathrm{hPa}$ (Figs. 3i-1), which might be related to the anomalous $500-\mathrm{hPa}$ ascent and anomalous $200-\mathrm{hPa}$ anticyclonic circulation to the north. These results imply that reduced water vapor flux convergence is responsible for reduced cloud cover and precipitation, since local evaporation increases. The related large-scale circulation variability will be addressed in section $3 \mathrm{c}$.

Therefore, enhanced solar radiation and surface wind speeds and reduced precipitation appear from pentad -2 to pentad 0 , are associated with concurrent anomalies of the key factors for HDEs: increased Tas, increased ET, and reduced SM.

\section{2) Central And EAstern China}

The regional processes related to HDEs over CEC are similar to those over SC. By comparing the development and decay phases of the key factors over CEC (Fig. 4) with those over SC (Fig. 2), we noticed the durations of the anomalous key factors over CEC are at least one pentad shorter. For example, as shown in Figs. $4 \mathrm{a}-\mathrm{d}$, the anomalously warm Tas begins in pentad -1 and diminishes in pentad +1 . The warmer Tas coincides with anomalously dry SM (Figs. 4e-h) and stronger ET (Figs. 4i-1). Since the anomalies of the key factors over CEC 

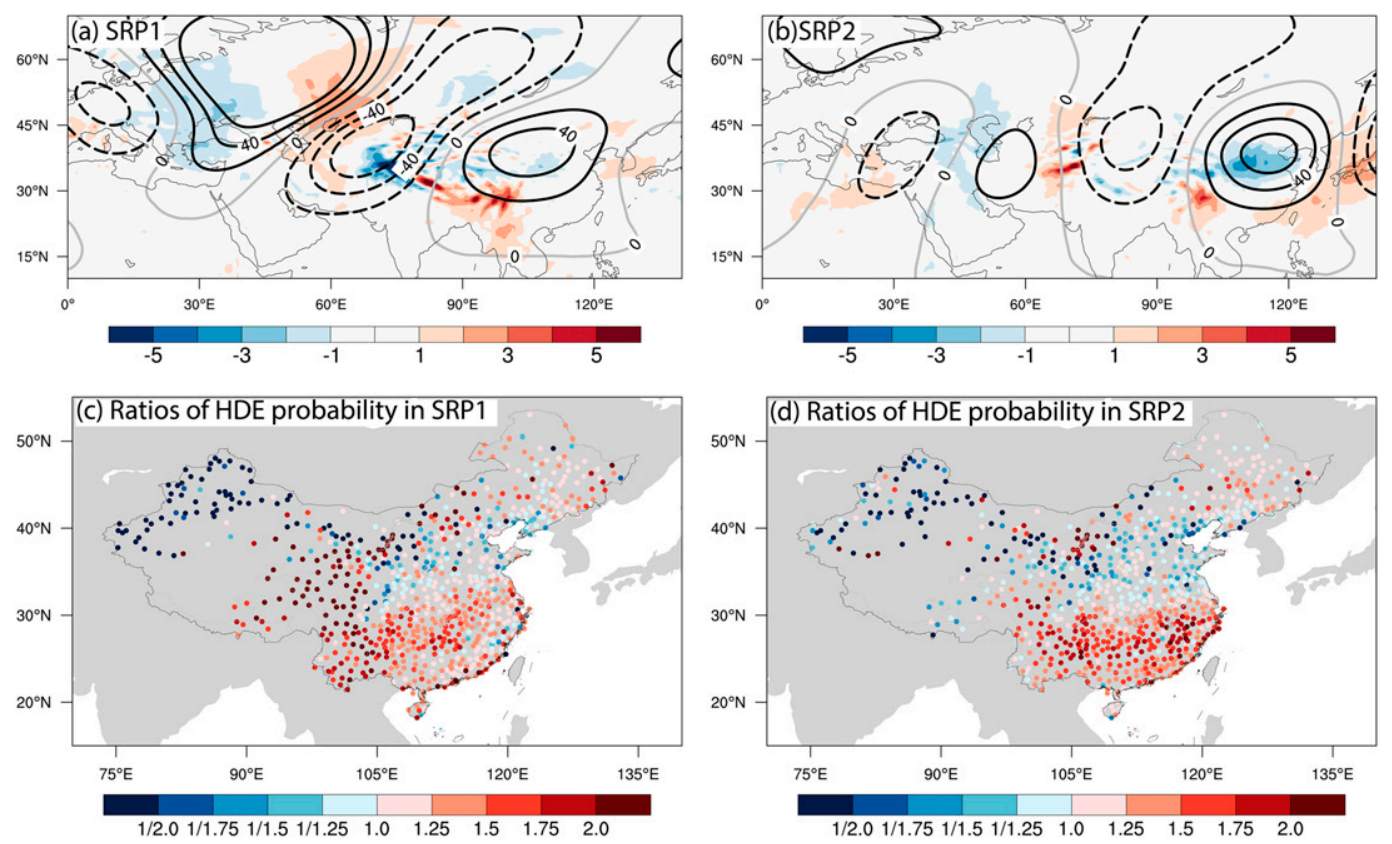

FIG. 7. (a) Spatial structure of the first leading EOF mode of Silk Road pattern (SRP1). Contours indicate geopotential height anomaly at $200 \mathrm{hPa}(\mathrm{m})$; colors indicate anomalies of vertical velocity $\left(10^{-2} \mathrm{~Pa} \mathrm{~s}^{-1}\right)$. (c) Ratios of probability of HDE when SRP1 index is larger than one standard deviation, divided by the climatological probability. (b),(d) As in (a) and (c), but for the second leading EOF mode of the Silk Road pattern (SRP2).

are about one pentad shorter than the duration over SC, the duration of HDEs is shorter as well (Fig. 1b). Note that the duration of HDEs is strongly related to, but not necessarily equal to, the durations of the key factors. This is because Fig. 4 shows mean anomalies, but the HDE criteria are based on anomalies of specific magnitudes (e.g., one standard deviation for Tas; the 40th percentile for SM).

The processes leading to the anomalies of the key factors over CEC are similar to those over SC. The stronger solar radiation (Figs. 5a-d) and less precipitation (Figs. 5e-h) begin at pentad -1 and pentad 0 , associated with simultaneous anomalies of Tas, SM, and ET, and hence with HDEs.

Over CEC, stronger solar radiation is related to less cloud cover, which is also related to anomalous 500-hPa subsidence (Figs. 5i-1). However, the anticyclonic circulation anomaly north of the anomalous subsidence moves from west to east between pentad -1 and pentad +1 . For SC HDEs, the anticyclonic circulation anomaly remains stationary between pentad -1 and pentad +1 (Figs. 3i-1). The changes in surface wind speeds over CEC (Figs. 5m-p) are small relative to those over SC (Figs. 3m-p). This implies that the enhanced ET is dominated by the increased energy source from stronger solar radiation and is amplified by warmer Tas.

Therefore, HDEs over CEC are associated with similar regional processes as over SC. The negative anomaly of cloud cover is related to stronger solar radiation and less precipitation, which are associated with simultaneous anomalies of the key factors of HDEs. But the average duration of the anomalies of the key factors is one pentad shorter, related to the shorter average duration of HDEs over CEC.

\section{c. Large-scale atmospheric circulation variability}

By analyzing the developing processes of the key factors at regional scale, we find that the simultaneous occurrence of less cloud cover and precipitation, strong solar radiation, and high wind speed is crucial for the occurrence of HDEs. However, these conditions are not driven entirely by local feedbacks. For example, only $20 \%$ of precipitation in East Asia comes from local evaporation (Guo et al. 2018). This implies that HDEs may be related to largescale circulation anomalies. The positive height anomaly at $200 \mathrm{hPa}$ is a crucial factor for increasing the probability of HDEs. We assume that if a large-scale subseasonal circulation variation can lead to a positive height anomaly at $200 \mathrm{hPa}$ over China, this circulation change may increase the probability of HDEs. This hypothesis is tested in the following subsections.

\section{1) SILK ROAD PATTERN}

Over CEC and SC, HDEs are connected to variations in large-scale atmospheric circulation. To investigate these connections, the vertical velocity at $500 \mathrm{hPa}$ and geopotential height anomalies at $200 \mathrm{hPa}$ are composited from pentad -2 to pentad +1 . The composite shows that in both SC and CEC the peak events of HDEs are related to a midlatitude wave train resembling the Silk Road pattern, propagating from Europe to East Asia (Fig. 6). In pentad 0, the anticyclonic circulation anomalies maximize over China.

The composite from SC pentad 0 shows the center of the anticyclonic circulation anomaly at $35^{\circ} \mathrm{N}$, extending south to 

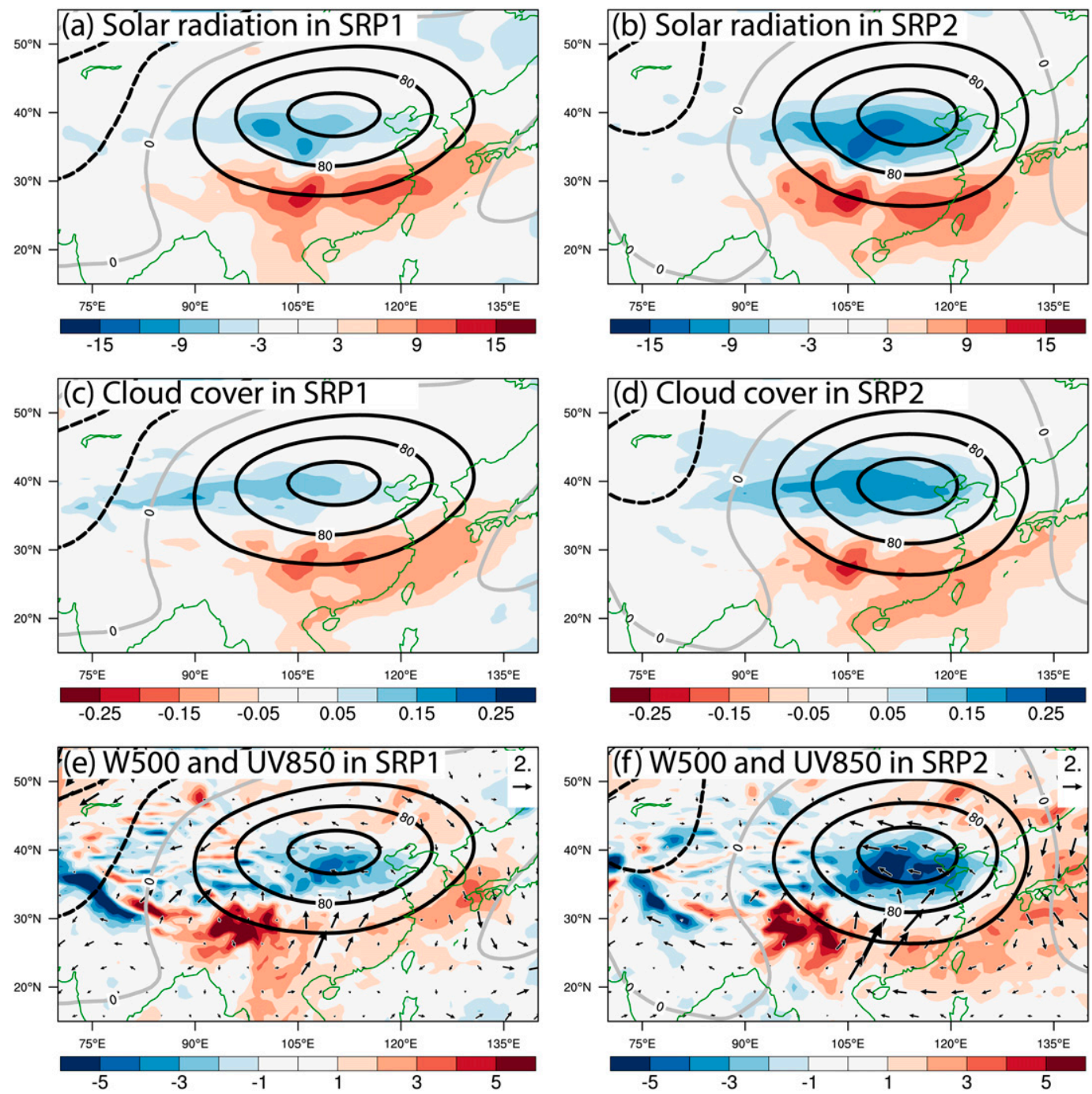

FIG. 8. (a),(b) Composited anomalies of surface net solar radiation (colors; $\mathrm{W} \mathrm{m}^{-2}$ ) and 200-hPa geopotential height (contours; m) based on (a) SRP1 index $>+1$ STD and (b) SRP2 index $>+1$ STD. (c),(d) As in (a) and (b), but for composited total cloud cover. (e),(f) As in (a) and (b), but for composed vertical velocity (colors; $10^{-2} \mathrm{~Pa} \mathrm{~s}^{-1}$ ) and horizontal wind field at $850 \mathrm{hPa}$ (arrows; $\mathrm{m} \mathrm{s}^{-1}$ ).

$20^{\circ} \mathrm{N}$ (Fig. 6e). This high anomaly develops in the same region at pentad -2 , but is very weak (Fig. 6a). At pentad +1 , it weakens rapidly (Fig. 6g). Therefore, the circulation anomalies related to SC HDEs resemble a standing wave. To the south of the $200-\mathrm{hPa}$ anticyclonic circulation anomaly is anomalous subsidence, which is consistent with $\mathrm{He}$ et al. (2018). The anomalous subsidence is related to the simultaneous occurrence of reduced precipitation and cloud cover and stronger solar radiation, which is crucial for HDE development. The composite from CEC HDEs shows an anticyclonic circulation anomaly centered at $40^{\circ} \mathrm{N}$, with anomalous subsidence at the southern boundary at $30^{\circ} \mathrm{N}$ (Fig. 6f). The lead-lag composite shows that the circulation anomalies move southeastward slowly. The center of the high anomaly moves from $45^{\circ} \mathrm{N}, 70^{\circ} \mathrm{E}$ at pentad -2 (Fig. $6 \mathrm{~b}$ ) to $42^{\circ} \mathrm{N}, 90^{\circ} \mathrm{E}$ at pentad -1 (Fig. $6 \mathrm{~d}$ ), and reaches $40^{\circ} \mathrm{N}, 100^{\circ} \mathrm{E}$ at pentad 0 (Fig. 6f). At pentad +1
(Fig. 6h), it diminishes and moves over the ocean $\left(38^{\circ} \mathrm{N}\right.$, $\left.120^{\circ} \mathrm{E}\right)$. Therefore, the distinctions between the circulation anomalies related to SC and CEC HDEs lie in the meridional displacements and the propagation speeds of wavelike upperlevel circulation anomalies. Both the meridional displacements and the propagation speeds are related to the strength and position of the Asian jet, which is a Rossby waveguide (Hoskins and Ambrizzi 1993).

Since the above analysis indicates that the occurrence of HDEs is related to midlatitude wave patterns, we investigate whether HDE frequency is affected by the strength of the Silk Road pattern, which is a midlatitude wave pattern spanning across the Eurasian continent roughly along $40^{\circ} \mathrm{N}$. We first obtained the SRP1 and SRP2 based on the definition from Yasui and Watanabe (2010). Strong SRP pentads are defined when the SRP1 and SPR2 index is larger than the mean plus 

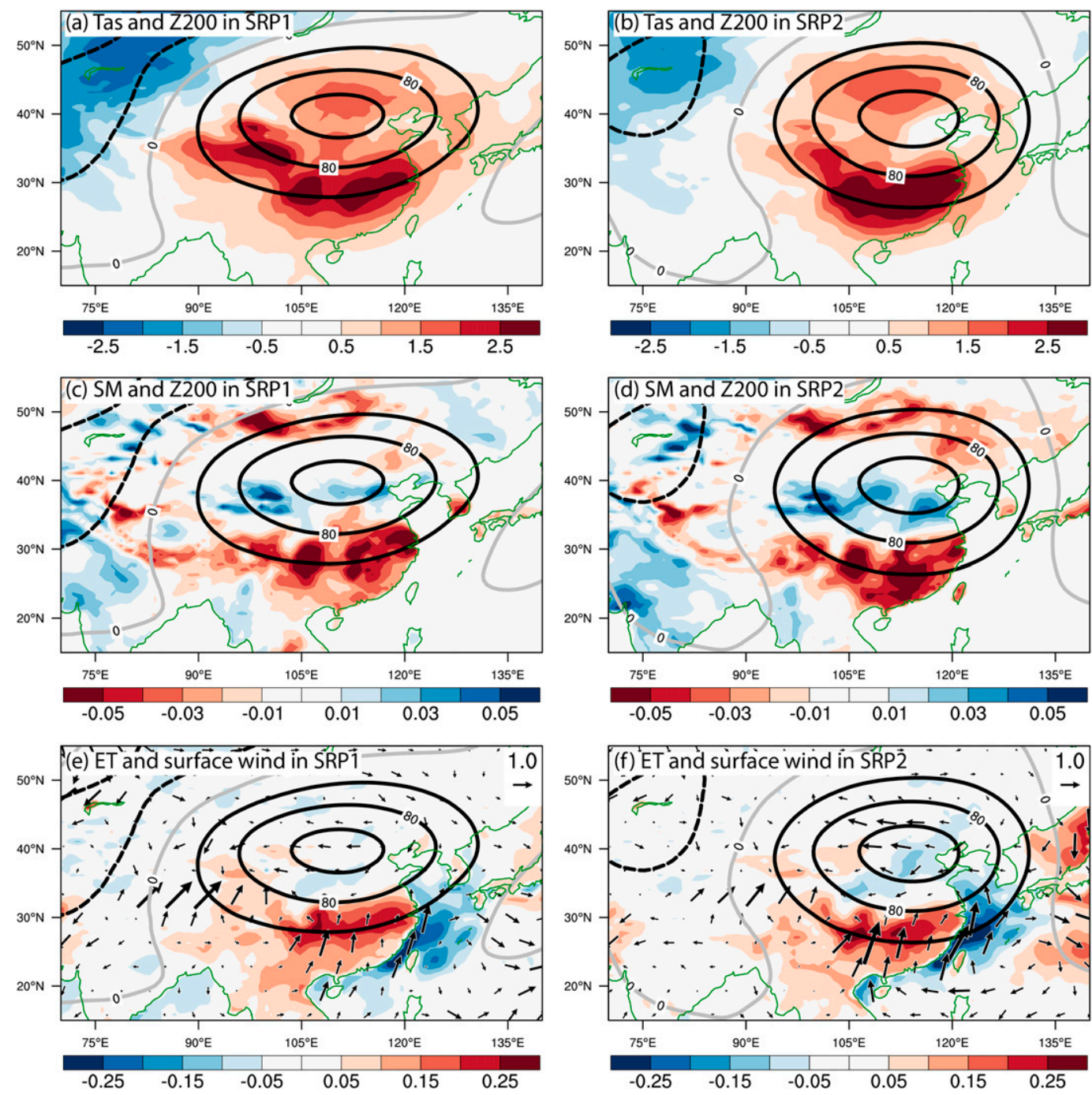

FIG. 9. (a),(c),(e) Composited circulation field based on SRP1 index larger than one standard deviation. (b),(d),(f) As in (a), (c), and (e), but based on SRP2 index larger than one standard deviation. Colors in (a) and (b) indicate anomalies of Tas $\left({ }^{\circ} \mathrm{C}\right)$, in (c) and (d) indicate anomalies of SM $\left(\mathrm{m}^{3} \mathrm{~m}^{-3}\right)$, and in (e) and (f) indicate the anomalies of ET $\left(\mathrm{mm} \mathrm{day}^{-1}\right)$. Arrows indicate horizontal $10-\mathrm{m}$ wind field $\left(\mathrm{m} \mathrm{s}^{-1}\right)$. Contours indicate anomalies of geopotential height $(\mathrm{m})$ at $200 \mathrm{hPa}$.

one standard deviation. Anomalous 200-hPa geopotential height and 500-hPa vertical velocity are composited in pentads with strong SRP1 and SRP2 (Figs. 7a,b). In both positive SRP1 and SRP2, there is an anticyclonic circulation anomaly over China. To quantify the effect of SRP on HDE frequency, we calculate the ratio of HDE frequency in the pentads with strong SRP, relative to the climate mean. Strong SRP1 and SRP2 are related to a greater risk of HDEs. Over the region south of $30^{\circ} \mathrm{N}$, positive SRP1 increases HDE frequency by approximately $40 \%$ (Fig. 7c). Positive SRP2 is related to an increase in HDE frequency of about 54\% above climatology (Fig. 7d).

In pentads with SRP1-related HDEs, the composite solar radiation is enhanced south of the positive height anomaly (Fig. 8a). The anomalously high solar radiation is located south of $30^{\circ} \mathrm{N}$, with the maximum along the Yangtze River, consistent with the decreased cloud cover over the same region (Fig. 8c) and 500-hPa subsidence anomaly to the south of the positive height anomaly. The stronger solar radiation leads to higher Tas (Fig. 9a). Stronger solar radiation and warmer Tas can enhance ET (Fig. 9e). Additionally, the composite 10-m wind anomaly is southerly (arrows in Fig. 9e), which enhances the climatological wind speed in April-October and may further amplify ET. Less cloud cover (Fig. 8c) is associated with less precipitation and is related to reduced SM (Fig. 9c). Reduced SM can be further amplified by the enhanced ET (Fig. 9e).

The physical processes related to SRP2 are similar to those for SRP1. The difference is that the height anomaly at $200 \mathrm{hPa}$ over China related to SRP2 is meridionally wider than that 

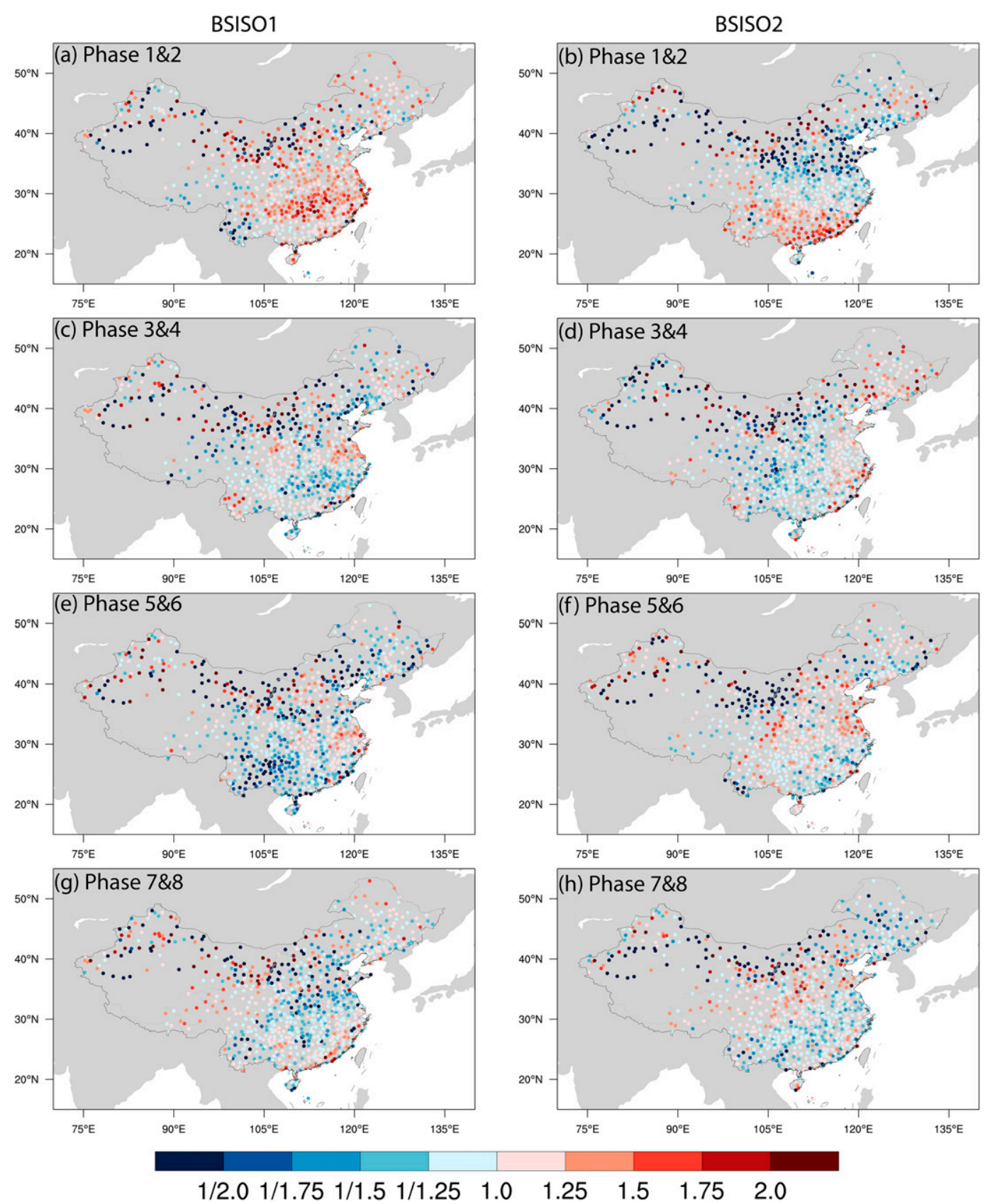

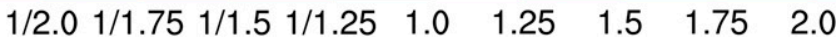

FIG. 10. Ratios of probability of HDE frequency in the eight phases of (left) BSISO1 and (right) BSISO2 related to the climatological probability in climate state. For each phase of BSISO1, the cases are selected when the amplitude $\left(\mathrm{PC1}^{2}+\right.$ $\left.\mathrm{PC}^{2}\right)^{1 / 2}$ exceeded 1; for each phase of BSISO2, the cases are selected when the amplitude $\left(\mathrm{PC} 3^{2}+\mathrm{PC}^{2}\right)^{1 / 2}$ exceeded 1. Shown are (a),(b) phases 1 and 2, (c),(d) phases 3 and 4, (e),(f) phases 5 and 6, and (g),(h) phases 7 and 8.

related to SRP1. The southern boundary of the 40-m geopotential height anomaly contour is over CEC along the Yangtze River in SRP1 $\left(28^{\circ} \mathrm{N}\right)$, but over SC in SRP2 $\left(26^{\circ} \mathrm{N}\right)$. The positive anomaly of solar radiation in SRP2 lies over $\mathrm{SC}$, with a maximum at $25^{\circ} \mathrm{N}$, and is consistent with reduced cloud cover. Related to the circulation anomaly, the key factors of HDEs related to SRP2 are found mainly over SC. This is consistent with the higher
HDE frequency in stronger SRP2 (Fig. 7d), particularly south of the Yangtze River.

\section{2) BSISO}

The duration of HDEs is between 5 and 10 days, indicating the development can be modified by the intraseasonal variability of the large-scale circulation. In the tropics, intraseasonal variability is controlled mainly by the BSISO. To 

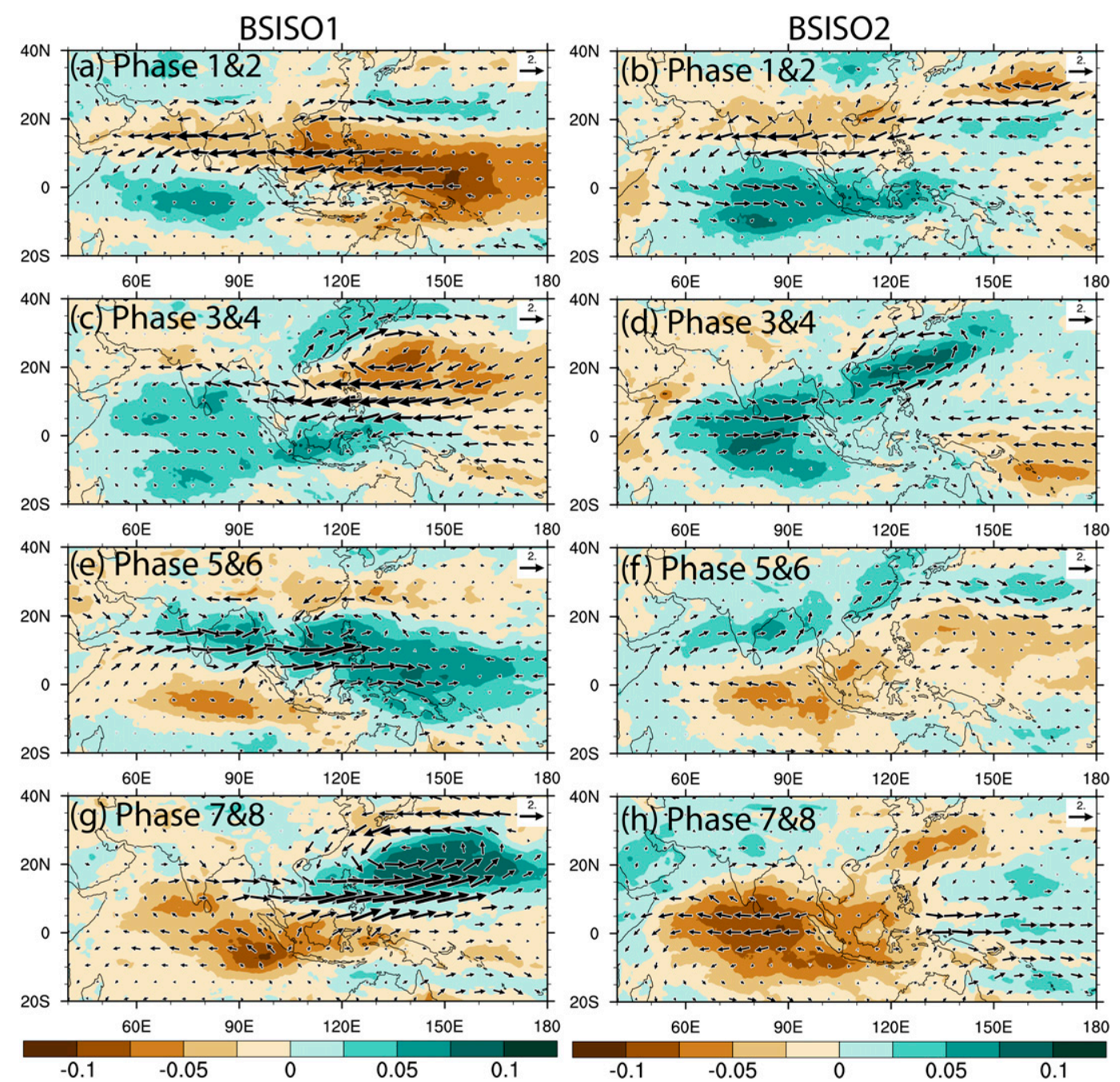

FIG. 11. Composite anomalies of total cloud cover (colors) and 850-hPa wind (arrows) when the (left) BSISO1 or (right) BSISO2 amplitude is larger than one: (a),(b) phases 1 and 2, (c),(d) phases 3 and 4, (e),(f) phases 5 and 6, and (g),(h) phases 7 and 8.

understand the relationship between BSISO and HDEs, we calculated the ratio of probability of HDEs in eight phases of BSISO1 and BSISO2, relative to the climatological probability (Fig. 10). The largest enhancement of HDE probability happens in phases 1 and 2 of both BSISO1 and BSISO2 (Figs. 10a,b). During BSISO1 phases 1 and 2, the probability of HDEs over CEC increases by $34.8 \%$. During BSISO2 phases 1 and 2, the probability of HDEs over SC increases by $34.5 \%$.

Composite anomalies of cloud cover and $850-\mathrm{hPa}$ wind in BSISO1 phases 1 and 2 show an anticyclonic circulation anomaly over SC and the South China Sea (SCS), and reduced of cloud cover along the Yangtze River and over SC (Fig. 11a). These anomalies are consistent with a positive height anomaly at $200 \mathrm{hPa}$ (contours in Fig. 12). This height anomaly is centered around $110^{\circ} \mathrm{E}$ in BSISO1; it extends across a large region of North China. At the southern edge of the positive height anomaly are subsidence anomalies along the Yangtze River in BSISO1 (Fig. 12c), which are consistent with the reduced cloud cover (Fig. 11a), stronger solar radiation (Fig. 12a), and warmer Tas (Fig. 13a). Additionally, the southerly wind anomaly over SC (Fig. 11a) enhances the climatological surface wind speed (Fig. 12e). The ET is enhanced by larger solar radiation, warmer Tas, and stronger surface wind speed. Reduced cloud cover is consistent with reduced precipitation and SM (Fig. 13c). The enhanced ET may further amplify the dry anomaly.

Therefore, there is a positive height anomaly at $200 \mathrm{hPa}$ over China in BSISO1 phases 1 and 2. The related circulation anomalies lead to concurrent anomalies of the key factors of HDEs. This is consistent with the increased HDE probability along the Yangtze River in the first two phases of BSISO1 (Fig. 10a).

For BSISO2, the circulation field in the first two phases (Fig. 11b) shows similar physical processes as those in 

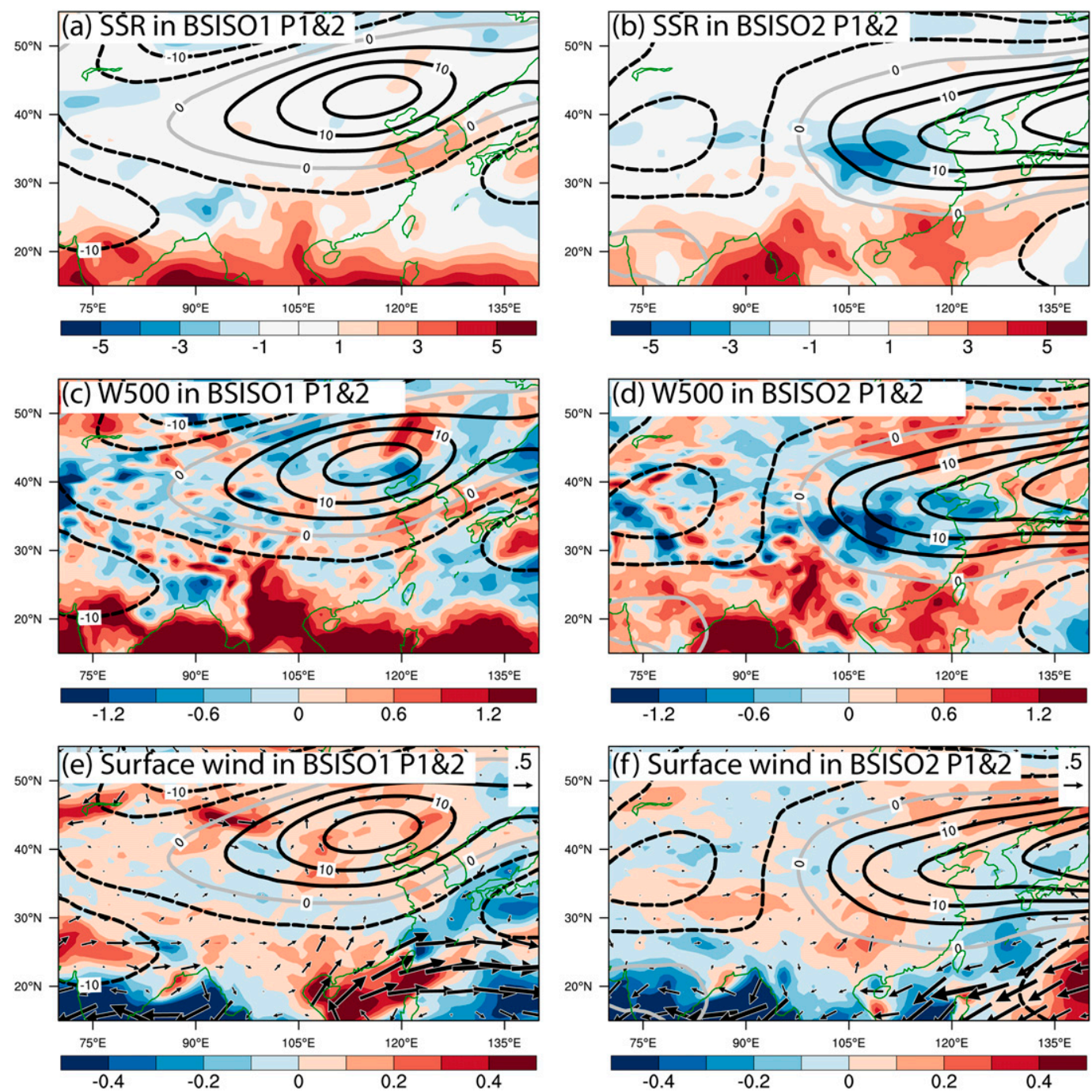

FIG. 12. (a),(c),(e) Composite 200-hPa geopotential height (contour; m), surface net solar radiation (colors; $\mathrm{W} \mathrm{m}{ }^{-2}$ ), 500-hPa vertical velocity (colors; $10^{-2} \mathrm{~Pa} \mathrm{~s}^{-1}$ ), and surface wind (arrows; $\mathrm{m} \mathrm{s}^{-1}$ ) and wind speed (colors; $\mathrm{m} \mathrm{s}^{-1}$ ) based on phases 1 and 2 of BSISO1 with amplitude larger than one. (b),(d),(f) As in (a), (c), and (e), but for BSISO2 amplitude.

BSISO1. The difference is that the anticyclonic circulation anomaly at $850 \mathrm{hPa}$ and the decreased cloud cover are located farther south in BSISO2 (SC and the South China Sea) than in BSISO1 (large area of CEC). This is associated with the position of the southern edge of the geopotential height anomaly in BSISO2, which is found over SC (Fig. 12). Therefore, the southward shift of the anomalous circulation in BSISO2, relative to BSISO1, shifts the anomalies of the key factors farther south. This is consistent with the HDE frequency, which increases over CEC in BSISIO1 and over SC in BSISO2.

The BSISO is the dominant mode of tropical subseasonal atmospheric circulation variability. The BSISO1 is active during the entire warm season from May to October (Lee et al. 2013), which is consistent with the weaker seasonality of HDE frequency over CEC in Fig. 1c. BSISO2 is much more active during the premonsoon and monsoon onset period. This might be related to the stronger seasonality of HDE frequency over SC (Fig. 1c), which shows that HDEs happen more frequently in the premonsoon (April) and after monsoon onset (July and August).

\section{Discussion}

Heatwave flash droughts are rapidly developing concurrent hot and dry events that have received much attention worldwide recently, due to their impacts on agriculture, water resources, and ecosystems (Ford and Labosier 2017; Mo and Lettenmaier 2015; Wang and Yuan 2018). This work analyzed how the frequency of concurrent hot and dry events relates to large-scale seasonal and subseasonal circulation variability, to aid in the physical understanding and prediction of these 

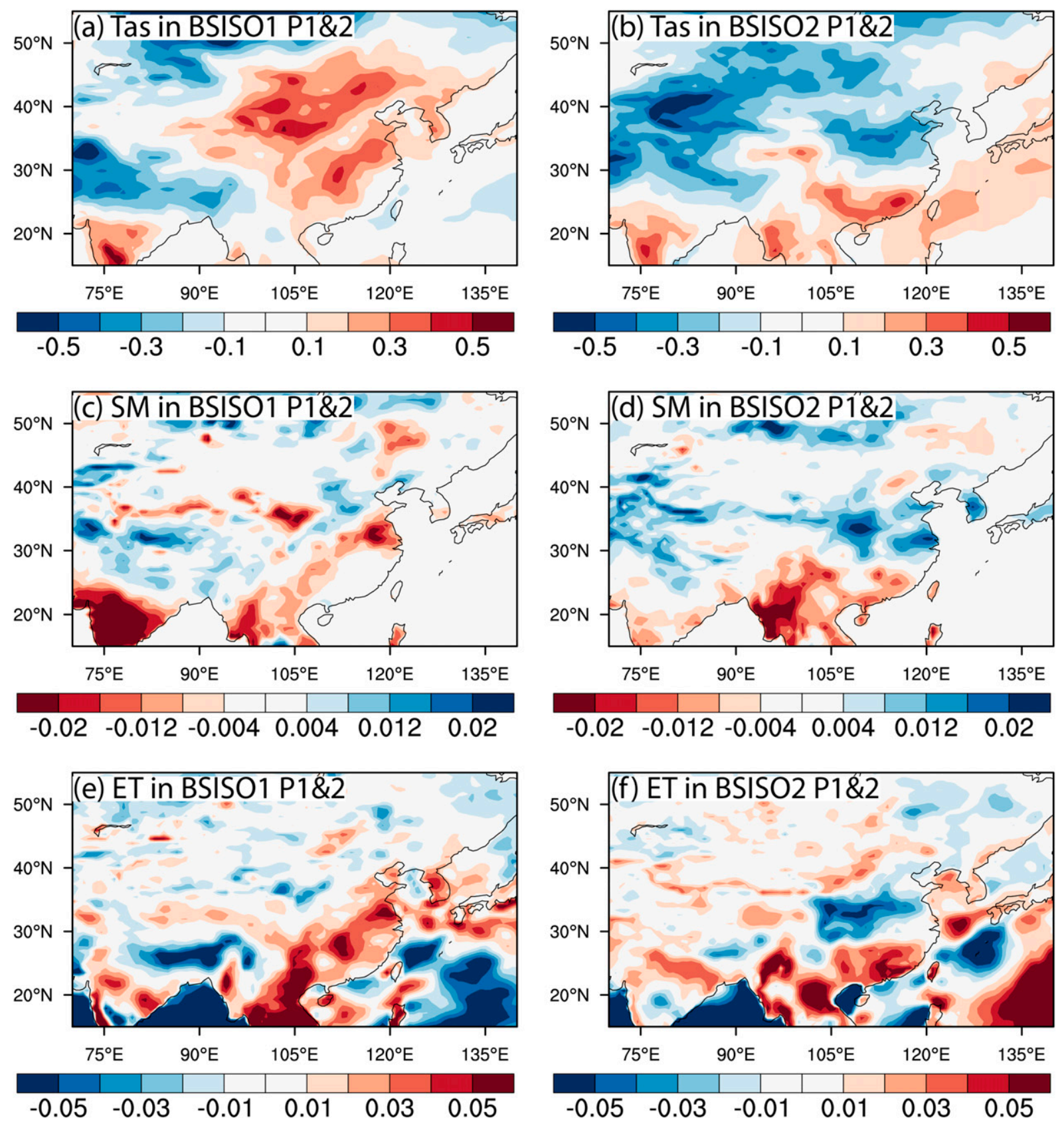

FIG. 13. (a),(c),(e) Composite Tas $\left({ }^{\circ} \mathrm{C}\right), \mathrm{SM}\left(\mathrm{m}^{3} \mathrm{~m}^{-3}\right)$, and ET $\left(\mathrm{mm} \mathrm{day}^{-1}\right)$ based on phases 1 and 2 of BSISO1 with amplitude larger than one. (b),(d),(f) As in (a), (c), and (e), but for BSISO2 amplitude.

events. Our results can be used to understand heatwave flash droughts, a subset of the full set of HDEs.

Our work shows that HDE development in China is often closely related to an anticyclonic circulation anomaly at $200 \mathrm{hPa}$. The subsidence anomaly related to the circulation anomaly can lead to simultaneously reduced cloud cover, lower near-surface humidity, and stronger surface winds, which may increase HDE risk.

We further link this mechanism with two well-known teleconnection patterns, SRP and BSISO, for which numerical weather prediction and subseasonal forecast systems have reasonable forecast performance (e.g., Jie et al. 2017; Neena et al. 2017). For example, the $200-\mathrm{hPa}$ anticyclonic circulation anomaly can be triggered in positive SRP1 and SRP2, and in phases 1 and 2 of BSISO1 and BSISO2. Our work bridges the relationships between HDEs and the SRP and the BSISO, so that one can apply many previous studies about SRP variability (Mao and Chan 2005, Mao et al. 2010, Lee et al. 2013, Li et al. 2018) and BSISO variability (Lee et al. 2013; Kiladis et al. 2014; Wang et al. 2018) to improve HDE predictions over China. 
Since our BSISO-HDE and SRP-HDE links are based on composite analysis, we cannot guarantee that the BSISO or SRP and HDEs will happen in the specific same pentad. However, this study reveals the internally consistent physical processes of HDEs and their associations with large-scale circulation variability, which will improve early warnings for rapidly developing HDEs (i.e., heatwave flash droughts). These diagnostics and teleconnections shown here can also be applied to evaluate climate model representations of HDEs and their mechanisms.

\section{Conclusions}

The heatwave-driven concurrent hot and dry extreme events (HDEs) during the growing season can damage crops. In contrast to conventional droughts, the physical processes of HDEs and their relationships to large-scale atmospheric circulation variability are not well understood; there is often no early warning and hence no opportunity to mitigate losses. Therefore, this work aimed to understand the driving processes of HDEs over China. Our main conclusions are as follows:

1) HDEs are observed at all stations in China. Central and eastern China (CEC) and southern China (SC) show the highest HDE frequency, in excess of 2.5 events per year. The average duration of HDEs over SC is longer than that over CEC; there are more HDEs that last longer than two pentads in $\mathrm{SC}$ than in CEC.

2) Over SC, HDEs are related to a midlatitude 200-hPa anticyclonic circulation anomaly with anomalous subsidence to its south, which is related to less precipitation and cloud cover, and enhanced solar radiation and surface wind speed. The reduced cloud cover and decreased precipitation result from anomalous water vapor transport divergence related to the circulation changes. The processes leading to the anomalies of the key factors of HDEs over CEC are similar to those for SC, but the duration of the anomalies of the key factors is one pentad shorter than over SC, associated with a shorter mean duration of HDEs in CEC.

3) Over a large region including SC and CEC, $40 \%-54 \%$ more HDEs happen during a strong positive phase of the Silk Road pattern (SRP). The positive SRP is associated with an anomalous anticyclonic circulation at $200 \mathrm{hPa}$ with a subsidence anomaly to its south over SC and CEC.

4) The distribution and seasonality of HDEs are related to the boreal summer intraseasonal oscillation (BSISO). Suppressed phases of the BSISO increase HDE frequency. Phases 1 and 2 of BSISO1, which are active during the whole growing season, are related a $34.8 \%$ increase in the frequency of HDEs averaged in CEC. In the premonsoon and monsoon onset season, phases 1 and 2 of BSISO 2 increase HDE frequency by about $34.5 \%$ averaged in SC.

Acknowledgments. FT and BD were supported by the U.K.China Research and Innovation Partnership Fund through the RICHES project of the Met Office Climate Science for Service
Partnership (CSSP) China as part of the Newton Fund. NPK was supported by an Independent Research Fellowship from the U.K. Natural Environment Research Council (NE/L010976/1). $\mathrm{BD}$ and NPK are also supported by the ACREW program of the U.K. National Centre for Atmospheric Science. The authors thank the anonymous reviewers for their constructive comments on the earlier version of the paper.

\section{REFERENCES}

Chen, Y., and P. Zhai, 2017: Simultaneous modulations of precipitation and temperature extremes in southern parts of China by the boreal summer intraseasonal oscillation. Climate Dyn., 49, 3363-3381, https://doi.org/10.1007/s00382-016-3518-4.

Dai, A., 2011: Drought under global warming: A review. Wiley Interdiscipl. Rev.: Climate Change, 2, 45-65, https://doi.org/ 10.1002/wcc.81.

Dee, D. P., and Coauthors, 2011: The ERA-Interim reanalysis: Configuration and performance of the data assimilation system. Quart. J. Roy. Meteor. Soc., 137, 553-597, https://doi.org/ 10.1002/qj.828.

Ford, T. W., and C. F. Labosier, 2017: Meteorological conditions associated with the onset of flash droughts in the eastern United States. Agric. For. Meteor., 247, 414-423, https:// doi.org/10.1016/j.agrformet.2017.08.031.

Fujinami, H., and T. Yasunari, 2004: Submonthly variability of convection and circulation over and around the Tibetan Plateau during the boreal summer. J. Meteor. Soc. Japan, 82, 1545-1564, https://doi.org/10.2151/jmsj.82.1545.

Guo, L., N. P. Klingaman, M. E. Demory, P. L. Vidale, A. G. Turner, and C. C. Stephan, 2018: The contributions of local and remote atmospheric moisture fluxes to East Asian precipitation and its variability. Climate Dyn., 51, 4139-4156, https://doi.org/10.1007/s00382-017-4064-4.

He, S., Y. Gao, T. Furevik, H. Wang, and F. Li, 2018: Teleconnection between sea ice in the Barents Sea in June and the Silk Road, Pacific-Japan and East Asian rainfall patterns in August. Adv. Atmos. Sci., 35, 52-64, https://doi.org/10.1007/ s00376-017-7029-y.

Hoskins, B. J., and T. Ambrizzi, 1993: Rossby wave propagation on a realistic longitudinally varying flow. J. Atmos. Sci., 50, 1661-1671, https://doi.org/10.1175/1520-0469(1993)050<1661: RWPOAR $>2.0 . \mathrm{CO} ; 2$.

Hunt, E. D., K. G. Hubbard, D. A. Wilhite, T. J. Arkebauer, and A. L. Dutcher, 2009: The development and evaluation of a soil moisture index. Int. J. Climatol., 29, 747-759, https://doi.org/ 10.1002/joc. 1749 .

Jie, W., F. Vitart, T. Wu, and X. Liu, 2017: Simulations of the Asian summer monsoon in the sub-seasonal to seasonal prediction project (S2S) database. Quart. J. Roy. Meteor. Soc., 143, 22822295, https://doi.org/10.1002/qj.3085.

Kiladis, G. N., J. Dias, K. H. Straub, M. C. Wheeler, S. N. Tulich, K. Kikuchi, K. M. Weickmann, and M. J. Ventrice, 2014: A comparison of OLR and circulation-based indices for tracking the MJO. Mon. Wea. Rev., 142, 1697-1715, https://doi.org/ 10.1175/MWR-D-13-00301.1.

Lee, J. Y., B. Wang, M. C. Wheeler, X. Fu, D. E. Waliser, and I. S. Kang, 2013: Real-time multivariate indices for the boreal summer intraseasonal oscillation over the Asian summer monsoon region. Climate Dyn., 40, 493-509, https://doi.org/ 10.1007/s00382-012-1544-4.

Li, X., G. Gollan, R. J. Greatbatch, and R. Lu, 2018: Intraseasonal variation of the East Asian summer monsoon associated with 
the Madden-Julian Oscillation. Atmos. Sci. Lett., 19, e794, https://doi.org/10.1002/asl.794.

Li, Z., L. Cao, Y. Zhu, and Z. Yan, 2016: Comparison of two homogenized datasets of daily maximum/mean/minimum temperature in China during 1960-2013. J. Meteor. Res., 30, 53-66, https://doi.org/10.1007/s13351-016-5054-x.

Mao, J., and J. C. Chan, 2005: Intraseasonal variability of the South China Sea summer monsoon. J. Climate, 18, 2388-2402, https://doi.org/10.1175/JCLI3395.1.

_ Z, Z. Sun, and G. Wu, 2010: 20-50-day oscillation of summer Yangtze rainfall in response to intraseasonal variations in the subtropical high over the western North Pacific and South China Sea. Climate Dyn., 34, 747-761, https://doi.org/10.1007/s00382-009-0628-2.

Mo, K. C., and D. P. Lettenmaier, 2015: Heat wave flash droughts in decline. Geophys. Res. Lett., 42, 2823-2829, https://doi.org/ 10.1002/2015GL064018.

Neena, J. M., D. Waliser, and X. Jiang, 2017: Model performance metrics and process diagnostics for boreal summer intraseasonal variability. Climate Dyn., 48, 1661-1683, https:// doi.org/10.1007/s00382-016-3166-8.

Otkin, J. A., M. C. Anderson, C. Hain, I. E. Mladenova, J. B. Basara, and M. Svoboda, 2013: Examining rapid onset drought development using the thermal infrared-based evaporative stress index. J. Hydrometeor., 14, 1057-1074, https://doi.org/ 10.1175/JHM-D-12-0144.1.

,,,--- and M. Svoboda, 2014: Examining the relationship between drought development and rapid changes in the evaporative stress index. J. Hydrometeor., 15, 938-956, https:// doi.org/10.1175/JHM-D-13-0110.1.

-, M. Shafer, M. Svoboda, B. Wardlow, M. C. Anderson, C. Hain, and J. Basara, 2015: Facilitating the use of drought early warning information through interactions with agricultural stakeholders. Bull. Amer. Meteor. Soc., 96, 1073-1078, https://doi.org/10.1175/BAMS-D-14-00219.1.

—, M. Svoboda, E. D. Hunt, T. W. Ford, M. C. Anderson, C. Hain, and J. B. Basara, 2018a: Flash droughts: A review and assessment of the challenges imposed by rapid-onset droughts in the United States. Bull. Amer. Meteor. Soc., 99, 911-919, https://doi.org/10.1175/BAMS-D-17-0149.1.

—, T. Haigh, A. Mucia, M. C. Anderson, and C. Hain, 2018b: Comparison of agricultural stakeholder survey results and drought monitoring datasets during the 2016 U.S. northern plains flash droughts. Wea. Climate Soc., 10, 867-883, https:// doi.org/10.1175/WCAS-D-18-0051.1.

Piao, S., and Coauthors, 2010: The impacts of climate change on water resources and agriculture in China. Nature, 467, 43-51, https://doi.org/10.1038/nature09364.
Sharma, S., and P. Mujumdar, 2017: Increasing frequency and spatial extent of concurrent meteorological droughts and heatwaves in India. Sci. Rep., 7, 15582, https://doi.org/10.1038/ s41598-017-15896-3.

Shukla, S., M. Safeeq, A. AghaKouchak, K. Guan, and C. Funk, 2015: Temperature impacts on the water year 2014 drought in California. Geophys. Res. Lett., 42, 4384-4393, https://doi.org/ 10.1002/2015GL063666.

Stanke, C., M. Kerac, C. Prudhomme, J. Medlock, and V. Murray, 2013: Health effects of drought: A systematic review of the evidence. PLOS Curr., 5, https://doi.org/ 10.1371/currents.dis.7a2cee9e980f91ad7697b570bcc4b004.

van Dijk, A. I. J. M., H. E. Beck, R. S. Crosbie, R. A. M. de Jeu, Y. Y. Liu, G. M. Podger, B. Timbal, and N. R. Viney, 2013: The Millennium Drought in southeast Australia (2001-2009): Natural and human causes and implications for water resources, ecosystems, economy, and society. Water Resour. Res., 49, 1040-1057, https://doi.org/10.1002/wrcr.20123.

Wang, L., and X. Yuan, 2018: Two types of FD and their connections with seasonal drought. Adv. Atmos. Sci., 35, 1478-1490, https://doi.org/10.1007/s00376-018-8047-0.

$\longrightarrow, \ldots$, Z. Xie, P. Wu, and Y. Li, 2016: Increasing flash droughts over China during the recent global warming hiatus. Sci. Rep., 6, 30571, https://doi.org/10.1038/srep30571.

Wang, S., D. Ma, A. H. Sobel, and M. K. Tippett, 2018: Propagation characteristics of BSISO indices. Geophys. Res. Lett., 45, 9934-9943, https://doi.org/10.1029/2018GL078321.

Yasui, S., and M. Watanabe, 2010: Forcing processes of the summertime circumglobal teleconnection pattern in a dry AGCM. J. Climate, 23, 2093-2114, https://doi.org/10.1175/ 2009JCLI3323.1.

Yuan, X., Z. Ma, M. Pan, and C. Shi, 2015: Microwave remote sensing of short-term droughts during crop growing seasons. Geophys. Res. Lett., 42, 4394-4401, https://doi.org/10.1002/ 2015 GL064125.

_- L. Wang, P. Wu, P. Ji, J. Sheffield, and M. Zhang, 2019: Anthropogenic shift towards higher risk of flash drought over China. Nat. Commun., 10, 4661, https://doi.org/10.1038/ s41467-019-12692-7.

Zhang, Q., P. Sun, J. Li, V. P. Singh, and J. Liu, 2015: Spatiotemporal properties of droughts and related impacts on agriculture in Xinjiang, China. Int. J. Climatol., 35, 1254-1266, https://doi.org/10.1002/joc.4052.

Zhang, Y., Q. You, C. Chen, and X. Li, 2017: Flash droughts in a typical humid and subtropical basin: A case study in the Gan River Basin, China. J. Hydrol., 551, 162-176, https://doi.org/ 10.1016/j.jhydrol.2017.05.044. 